\title{
VILLAR PALASÍ: SOBRE TECNOCRACIA Y DIRECCIÓN ESCOLAR
}

\section{Villar Palasí: about technocracy and school management}

\author{
Aurelio González Bertolín ${ }^{\alpha}$ y Roberto Sanz Ponce ${ }^{\beta}$
}

Fecha de recepción: 04/09/2020 • Fecha de aceptación: 01/02/2021

Resumen. El catedrático de universidad José Luis Villar Palasí llegó al Ministerio de Educación y Ciencia en abril de 1968, auspiciado por el sector tecnócrata del Gobierno, con el encargo político y la convicción personal de realizar una reforma de las estructuras universitarias que consiguiese apaciguar la creciente conflictividad en las aulas. Sin embargo, pronto comprendió que el arcaico sistema educativo español requería una reforma integral que lo homologase a los sistemas educativos avanzados del último tercio del siglo XX. Para llevar a cabo su propósito se rodeó de un equipo de técnicos solventes, muchos de ellos de perfil político independiente, y vinculados a agencias e instituciones internacionales. Este equipo ministerial realizó un diagnóstico de los desequilibrios y contradicciones del sistema educativo, así como una propuesta para la reforma educativa que sería recogida en el llamado Libro blanco. Este documento sirvió de base para la nueva ley de educación de 1970. Sin embargo, en lo que respecta a la dirección escolar, el texto de la ley se alejó de las propuestas del Libro blanco, suprimiendo el Cuerpo de Directores. En el presente trabajo realizamos una reflexión sobre las circunstancias ideológicas y políticas de la reforma educativa y del propio ministro Villar Palasí. Y tratamos de aportar algunas claves sobre las causas que motivaron la supresión del Cuerpo de Directores.

Palabras clave: franquismo y educación; tecnocracia en España; reforma educativa de 1970, dirección escolar en España.

\footnotetext{
^ Dpto. Didáctica General, Teoría de la Educación e Innovación Tecnológica, Facultad de Magisterio y CC. de la Educación, Universidad Católica de Valencia. C/ Sagrado Corazón, 5, 46110 (Godella), Valencia, España. aurelio.gonzalez@ucv.es (D) https://orcid.org/0000-0003-3167-297X

B Dpto. Didáctica General, Teoría de la Educación e Innovación Tecnológica, Facultad de Magisterio y CC. de la Educación, Universidad Católica de Valencia. C/ Sagrado Corazón, 5, 46110 (Godella), Valencia, España. roberto.sanz@ucv.es (D) https://orcid.org/0000-0003-1147-743X
} 
Abstract. University Professor José Luis Villar Palasí took charge of the Ministry of Science and Education in April 1968, after being nominated by the technocratic sector of the Government, with the political mission and personal conviction of reshaping the organisational structures of education in an attempt to stem the increasing unrest at universities. Nonetheless, he soon came to learn that the Spanish educational system as it stood required a complete renovation if it was to join the ranks of other advanced educational systems in the last quarter of the 20th century. In order to complete this task he recruited a team of qualified technocrats, most of them having independent political views and associations with international agencies and institutions. This ministerial team carried out a diagnosis of the imbalances and contradiction of the educational system at the time and then put forward a proposal for an educational reform, laid out in the so called Libro blanco (White Book). This document would become the foundational plan for the new General Education Act of 1970. However, regarding the matter of academic management, the wording of the Law deviated from the proposals made in Libro blanco, suppressing the Board of Directors. This work reflects on the ideological and political circumstances of the educational reform and Minister Villar Palasi himself. We also attempt to provide some clues as to the causes that led to the abolition of the Corps of Directors.

Keywords: francoism and education; technocracy in Spain; the 1970 educational reform; school management in Spain.

\section{VILLAR PALASÍ, MINISTRO ¿TECNÓCRATA? DE EDUCACIÓN Y CIENCIA}

Las circunstancias del nombramiento de Villar Palasí como ministro de Educación y Ciencia fueron, muy aproximadamente, las siguientes: su predecesor en el cargo, el catedrático jerezano Manuel Lora Tamayo, que había accedido al cargo en la crisis ministerial de 1962, se sentía desbordado por las protestas estudiantiles y la creciente agitación en las aulas, singularmente en las universidades de Madrid y Barcelona. En el mes de noviembre de 1967 presentó un extenso informe al jefe del Estado, en el que, entre otras consideraciones, apuntaba la conveniencia de dar por finalizada su gestión al frente del Ministerio.

En el mencionado escrito, Lora Tamayo reflexionaba sobre cómo el Ministerio de Educación sufría el impacto de las agitaciones políticas de la vida universitaria, circunstancia que generaba un particular desgaste de la figura de su titular. Debido a ello, consideraba que una renovación 
en el cargo produciría el efecto expectante de la novedad y permitiría reconsiderar el problema y acometer nuevas vías para su solución.

Proseguía el documento haciendo un somero repaso de lo que Lora Tamayo consideraba logros más relevantes de su gestión al frente del ministerio: la elevación de la escolaridad obligatoria hasta los catorce años, los buenos resultados de la campaña de alfabetización de adultos, la unificación del primer ciclo de Enseñanza Media, la estructuración departamental de las facultades universitarias, una nueva ordenación de las enseñanzas técnicas, la implantación de la orientación educativa, el fomento de la investigación y el aumento -multiplicación, se decía en el documento- de los centros docentes de todos los grados. Finalizaba el escrito al jefe del Estado sugiriendo el nombre de su posible sucesor en la cartera de Educación y Ciencia, Antonio Tena Artigas, en aquel momento secretario general técnico del ministerio. ${ }^{1}$

Franco recibió al ministro en audiencia y escuchó la lectura del escrito con aparente benevolencia, tras un prolongado silencio alabó lacónicamente la bonhomía de su interlocutor, se dio por enterado y dejó correr el asunto. Sin embargo, en las semanas siguientes la situación empeoró de manera ostensible. Diversos grupos de estudiantes organizaron actos de protesta y repartieron propaganda calificada por muchos como marxista y subversiva, circunstancia esta que, desde los sectores más ortodoxos del Movimiento, que ya recelaban de la capacidad de Lora Tamayo para hacer frente a la situación, fue atribuida a un incomprensible debilitamiento de la autoridad académica. En este estado de cosas, el ministro de la Gobernación, general Camilo Alonso Vega, dictó unas nuevas normas de actuación policial. Los mandos de la Policía Armada, ante cualquier alteración del orden en recinto universitario, podían ordenar la entrada de la fuerza pública en las facultades siempre que la autoridad académica no hubiese sido capaz de restablecer el orden en un breve plazo de tiempo.

\footnotetext{
${ }_{1}^{1}$ Antonio Tena Artigas era notario de profesión. Consideraba el ministro que no siendo catedrático de universidad, como lo era él mismo y lo habían sido sus predecesores en el cargo, pudiera actuar con más libertad de prejuicios a la hora de abordar las conflictivas relaciones del Gobierno con la universidad. Así se lo hizo notar al jefe del Estado. Manuel Lora Tamayo, Lo que yo he conocido. Recuerdos de un viejo catedrático que fue ministro (Cádiz: Ingrasa, 1993), 393.
} 
Como no podía ser de otro modo, esta medida indignó al ministro y a los decanos de las facultades. Pero era solamente el principio. A finales de marzo de 1968 la Policía Armada irrumpió en las facultades de Ciencias, Derecho y Económicas. En esta última, la fuerza pública cargó de manera indiscriminada golpeando al decano, a varios profesores y a un buen número de estudiantes. Lora Tamayo, informado por el rector Isidoro Martín, mantuvo una acalorada discusión telefónica con el ministro de la Gobernación, a resultas de la cual presentó, ya de manera irrevocable, su dimisión al jefe del Estado. En el documento enviado a Franco, entre otras cosas, se decía lo siguiente:

Este modo de proceder de la Policía no puede tener otra consecuencia que poner fuera del régimen a catedráticos que nos son afectos y aun determinar posiciones colectivas de enfrentamiento [...] me he quejado al Ministro de la Gobernación de todo ello y al no reconocer estos errores se rompe toda relación [...]. Por mi parte, mi General, he llegado al límite de mis posibilidades y resistencia, le ruego que mi petición de ser sustituido, solicitada desde meses atrás, la considere actualizada, relevándome desde ahora mismo del puesto de Ministro. ${ }^{2}$

Fiel a su proverbial costumbre de demorar la toma de decisiones, Franco se tomó algunas semanas para resolver sobre el asunto. Manejaba tres opciones: un reajuste ministerial cesando a los ministros de Gobernación y de Educación y Ciencia; aprovechar la crisis para realizar una amplia remodelación del gabinete; o limitarse a sustituir al ministro de Educación y Ciencia. Finalmente optó por esta última posibilidad, sustituyendo a Lora Tamayo por José Luis Villar Palasí el 18 de abril de 1968 y aplazando hasta octubre de 1969 la que sería una crisis ministerial de más amplio calado político.

Los sucesivos gobiernos del franquismo, por convicción y deseo expreso del jefe del Estado, mantuvieron una presencia constante de distintos grupos, más o menos organizados según los casos, que se correspondían con los sectores ideológicos que habían apoyado el levantamiento militar de 1936, «los gobiernos deben de tener una representación de las

2 Jesús Palacios Tapias, Las cartas de Franco (Madrid: La Esfera de los Libros, 2005), 482. 
fuerzas que han contribuido a la victoria", ${ }^{3}$ había dicho Franco. Y efectivamente, falangismo, carlismo, tradicionalismo y catolicismo político disponían de su cuota de poder en los sucesivos gobiernos; se trataba de lo que se ha dado en llamar familias del franquismo. ${ }^{4}$ De hecho, Franco ejerció un continuo arbitraje moderador entre todas ellas, contraponiendo a unas familias con otras para equilibrar el poder, aunque tratando de no suscribir personalmente ninguna de ellas en detrimento de las demás.

No obstante, desde el último tercio de los años cincuenta, coincidiendo con la pérdida de influencia de grupos como el falangismo de primera hora, el carlismo o el catolicismo político vinculado a la Asociación Católica Nacional de Propagandistas (ACN de P), comenzaron a llegar al Gobierno nuevas generaciones de altos cargos, de perfil ideológico más indefinido, que habían basado su carrera política en la preparación técnica personal y en la capacidad de gestión. Son los llamados tecnócratas, una nueva cohorte de altos funcionarios, profesores universitarios o profesionales liberales, algunos de ellos vinculados al Opus Dei.

A finales de los años cuarenta y comienzo de los cincuenta, frente al falangismo y al sector político vinculado a la ACN de P, comenzó a articularse una nueva élite política e intelectual, heredera en gran medida de Acción Española, ${ }^{5}$ vinculada a ámbitos de gran influencia del emergente Opus Dei, como las revistas Arbor y Atenea, la Editorial Rialp y el

\footnotetext{
${ }^{3}$ Francisco Franco Salgado-Araujo, Mis conversaciones privadas con Franco (Barcelona: Planeta, 1976, 230.

${ }^{4}$ El término fue acuñado por Amando de Miguel e hizo fortuna a partir de la publicación de su obra Sociología del franquismo; en ella se clasificaba a los políticos que habían desempeñado responsabilidades ministeriales durante el franquismo en militares, primorriveristas, tradicionalistas, monárquicos, falangistas, católicos, integristas, tecnócratas y técnicos. Amando de Miguel Rodríguez, Sociología del franquismo. Análisis ideológico de los Ministros del Régimen (Barcelona: Euros, 1975), 143-236.

${ }^{5}$ Acción Española no era, al menos formalmente, un partido político. Se trataba de un grupo de intelectuales que habían desempeñado cargos relevantes durante la dictadura de Primo de Rivera. Se articularon en torno a la revista del mismo nombre, Acción Española, cuyo primer número apareció en diciembre de 1931. Partidarios de la monarquía autoritaria y de la organización corporativa del Estado, asentaban sus bases ideológicas sobre una revisión y actualización del pensamiento tradicional español. Formaban parte del grupo, entre otros, Ramiro de Maeztu, Víctor Pradera, José Ibáñez Martín, José Pemartín, Eugenio Vegas Latapié, Pedro Saiz Rodríguez y José Calvo Sotelo. A juicio de Antonio Fontán, los hombres de Acción Española constituyeron durante los años de la Segunda República el más brillante equipo intelectual de la derecha española, y tuvieron una enorme influencia sobre el pensamiento político posterior de los grupos conservadores. Antonio Fontán Pérez, Los católicos en la Universidad española actual (Madrid: Rialp, 1961), 35.
} 
Consejo Superior de Investigaciones Científicas (CSIC). Esta corriente tuvo como principales ideólogos a Rafael Calvo Serer, Florentino Pérez-Embid, José María de Albareda o Gonzalo Fernández de la Mora, que defendían la solución monárquica corporativa como alternativa de futuro. A partir de la publicación en 1949 de la obra de Laín Entralgo España como problema ${ }^{6}$ se iniciaría un debate aparentemente científico y cultural, pero en el que de forma implícita se contraponían dos concepciones diferentes de entender el régimen. En la citada obra Laín Entralgo proponía la recuperación de la tradición liberal española, considerando que el régimen debía evolucionar incorporando a personas, grupos e ideologías excluidos como consecuencia del desenlace de la Guerra Civil. Por el contrario, Calvo Serer en su réplica, España sin problema, ${ }^{7}$ defendía el magisterio intelectual de Menéndez Pelayo, planteando la necesidad de incorporar las innovaciones que llegasen de fuera para conseguir una modernización de los medios técnicos, científicos y económicos, pero todo ello puesto al servicio de una empresa nacional y católica. Consideraba que la modernización del país debía partir de un proceso de desideologización. En nuestra opinión, la publicación de la obra de Calvo Serer supone el momento inicial del proceso de construcción de una corriente ideológica de tecnocracia a la española, que haría fortuna en la vida política del régimen durante los años sesenta y primeros setenta.

Si bien a la altura de los años cincuenta Calvo Serer defendía un programa tradicionalista basado en el integrismo católico, creemos que hay que considerarlo un precursor de una tecnocracia aparentemente neutralista. «La tecnocracia implica y propugna un cierto neutralismo ideológico. Es verdad que no hay tal neutralidad, pero con ella se evita la superideologización». ${ }^{8}$ Lo que preocupa a Calvo Serer en España sin problema no es la negación del problema en sí, sino un planteamiento según el cual esta cuestión -la superación del problema- es previa para la resolución de los problemas de España (educación, vertebración territorial, tecnología, homologación internacional) mediante la modernización de los medios

\footnotetext{
${ }^{6}$ Pedro Laín Entralgo, España como problema (Madrid: Escelicer, 1949).

${ }^{7}$ Rafael Calvo Serer, España sin problema (Madrid: Rialp, 1957).

${ }^{8}$ Elías Díaz García, Pensamiento español en la era de Franco (1939-1975) (Madrid: Tecnos, 1983), 57.
} 
científicos, técnicos y materiales. ${ }^{9} \mathrm{O}$ sea, tecnocracia en estado puro, si bien en su fase inicial. En frase, que haría fortuna, de Florentino Pérez-Embid, «españolización en los fines y europeización de los medios». ${ }^{10}$

Quizá sea oportuno recordar que el crecimiento económico experimentado por España a partir del Plan de Estabilización de 1959, favorecido por una excelente coyuntura internacional, tuvo como consecuencia una profunda transformación social, económica y en cierto modo política del país. Las formas de vivir, pensar, ganarse la vida y ocupar el ocio de los españoles evolucionaron de forma vertiginosa a lo largo de los años sesenta. Probablemente la España de 1960 se parecía más a la de 1900 que a la de 1970. «El cambio ocurrido en España en diez años equivalió en magnitudes relativas al que en conjunto había experimentado el país en los sesenta años anteriores». ${ }^{11}$

En este contexto, tal y como se ha dicho, el modelo tecnocrático suponía un intento de modernizar el Estado «trasladando al sector público los criterios propios de la empresa privada -racionalidad y eficacia-; [...] un intento de eludir las consecuencias derivadas de la libertad política, implantando en su lugar la libertad económica». ${ }^{12}$ Aun teniendo en cuenta las peculiaridades del régimen político en España, no se trata de un fenómeno estrictamente hispano. Tras la Segunda Guerra Mundial, el extraordinario desarrollo económico de Europa occidental, la construcción del Estado de bienestar y la planificación e intervención del Estado en la economía, propició la aparición y consolidación de unas nuevas élites tecnocráticas en las estructuras estatales, tanto en países con régimen político liberal, como en los socialistas o autoritarios. ${ }^{13}$ «Gusto por la eficiencia, inclinación por los métodos de trabajo propios de la empresa privada, exaltación del desarrollo económico, repudio de las ideologías,

\footnotetext{
9 Aurelio González Bertolín y Roberto Sanz Ponce, «"Excluyentes” y “comprensivos”. Joaquín Ruiz-Giménez y los orígenes de la extensión de la Enseñanza Media en España», Educació i Història 32 (2018): 96-99.

10 Florentino Pérez-Embid Tello, "Ante la nueva actualidad del "problema de España” ", Arbor 45-46 (1949): 159.

11 Gregorio Doval Huecas, Los últimos años del franquismo (1969-1975) (Madrid: Síntesis, 2007$), 39$.

12 Manuel de Puelles Benítez, Educación e ideología en la España contemporánea (Madrid: Tecnos, 1999), 329.

13 Pedro Carlos González Cuevas, «La derecha tecnocrática», Historia y Política: Ideas, Procesos y Movimientos Sociales 18 (2007): 23.
} 
paternalismo político, fe en la libre empresa» ${ }^{14}$ son características comunes entre la nueva clase tecnocrática española y sus homólogos europeos. Además, la expansión económica sostenible supuso un cambio sustancial en el discurso legitimador del régimen franquista, se pasó de la legitimidad de origen -la de la victoria- a la legitimad de ejercicio -la de las realizaciones- y se produjo un cambio de estilo en las clases dirigentes del régimen, la retórica grandilocuente y triunfalista de los primeros años, dio paso a un lenguaje técnico, empresarial y legalista. Las camisas azul mahón fueron mudando en camisas de cuello blanco.

Los gobiernos de 1965 y 1967 se caracterizaron por una cierta voluntad de aperturismo (Ley de Prensa) e institucionalización del régimen (Ley Orgánica del Estado). Suponen la consolidación de los tecnócratas en el gobierno y el apogeo del desarrollismo al amparo del crecimiento económico experimentado como consecuencia del I Plan de Desarrollo. En 1967 se aprobó la Ley Orgánica del Estado, según la cual se creaba la figura de presidente del Gobierno, cargo que hasta entonces había desempeñado el propio jefe del Estado. De igual modo se adoptaron diversas medidas institucionales dirigidas a afianzar la sucesión monárquica en la jefatura del Estado. Sin embargo, tal y como señalaba un destacado protagonista político del momento, «desde 1957 la lucha por el poder estaba claramente definida entre dos bandos, el del Movimiento y los sindicatos, por un lado, y el tecnocrático, por otro, compuesto en algunos casos más o menos significados por hombres del Opus Dei». ${ }^{15}$ No obstante, según la opinión de Tusell, en la segunda mitad de la década de los sesenta las tradicionales familias del franquismo se desdibujaron progresivamente, convirtiéndose en perfiles para proporcionar carreras políticas. Se asemejan a las clientelas, dice, tan solo unidas por una vaga identificación programática o interés de promoción política personal, «los tecnócratas fueron la clientela de Carrero Blanco, cuya influencia se hacía creciente y a quienes sus adversarios identificaron con el Opus Dei». 16

\footnotetext{
${ }_{14}$ Manuel de Puelles Benítez, «Tecnocracia y política en la reforma educativa de 1970», Revista de Educación n. ${ }^{\circ}$ ext. «La Ley General de Educación veinte años después» (1992): 16.

15 Federico Silva Muñoz, Memorias políticas (Barcelona: Planeta, 1993), 266.

16 Javier Tusell Gómez. , Historia de España en el siglo XX. III. La Dictadura de Franco (Madrid: Taurus, 2000), 484.
} 
Si algo se estaba poniendo de manifiesto a la altura de 1968, coincidiendo en el tiempo con el nombramiento de Villar Palasí como ministro de Educación y Ciencia, era la creciente rivalidad, tensión y aun enfrentamiento en el seno del Gobierno entre las distintas familias políticas. Villar Palasí llegó al Gobierno auspiciado por Carrero Blanco, vicepresidente del Gobierno en aquel momento y, sobre todo, por Laureano López Rodó, ${ }^{17}$ máximo representante del sector que se ha dado en llamar tecnócrata, imponiéndose así a Torcuato Fernández Miranda, candidato del grupo azul -un azul ya tenue a esas alturas del régimen- encabezado por falangistas que no habían hecho la Guerra, como Manuel Fraga Iribarne, Fernando María de Castiella y José Solís. Debemos señalar además que el principal objetivo político de Carrero Blanco, aparte de su absoluta, inquebrantable y granítica lealtad personal y política a Franco, era conseguir el nombramiento de Juan Carlos de Borbón como príncipe de España y heredero a título de Rey. Sin embargo, el nuevo Gobierno anunciado el 29 de octubre de 1969 rompía con la tradición del equilibrio de fuerzas entre las distintas familias políticas, reforzando de manera definitiva al grupo de los tecnócratas, liderado por López Rodó, que contaba con el decidido apoyo del hombre fuerte del régimen, Carrero Blanco. De hecho, este fue el primer Gobierno totalmente propuesto por Carrero Blanco, que no era partidario -acaso esta era su única discrepancia conocida con Franco- de la estrategia de repartir el equilibrio de poder entre las distintas familias. ${ }^{18}$

A nuestro juicio, el reajuste ministerial, que apenas seis meses antes había llevado a Villar Palasí al Consejo de Ministros, solo puede ser interpretado como un avance del que sería considerado como el primer Gobierno monocolor del franquismo. Así se deduce del análisis de las

\footnotetext{
17 «Puedo adelantar que he promovido el nombramiento de los siguientes Ministros: [...], Federico Silva Muñoz, Adolfo Díaz Ambrona, José Luís Villar Palasí...». Laureano López Rodó, Memorias (Barcelona: Plaza y Janés, 1990), 99.

${ }^{18}$ Fueron cesados Fraga, Castiella y Solís, ministros críticos con Carrero. Y llegaron al Gobierno destacados tecnócratas como Sánchez Bella (Información y Turismo), López de Letona (Industria), Monreal Luque (Hacienda), Mortes Alfonso (Vivienda), Allende García-Baxter (Agricultura), Fontana Codina (Comercio). Continuaron el Consejo de Ministros López Rodó (Plan de Desarrollo), Silva Muñoz (Obras Públicas), Oriol (Justicia) y el propio Villar Palasí. Los tres ministros de origen falangista García-Ramal (Organización Sindical), Licinio de la Fuente (Trabajo) y Torcuato Fernández Miranda (secretario general del Movimiento) eran políticos pragmáticos y dialogantes, capaces de mantener una fluida relación política con Carrero Blanco. Finalmente, el vehemente ministro de la Gobernación Camilo Alonso Vega, ya octogenario, fue sustituido por Tomás Garicano Goñi, general del Cuerpo Jurídico del Aire, aunque de talante mucho más moderado que su predecesor.
} 
circunstancias políticas del momento y de la trayectoria política del nuevo ministro. Es de todo punto incuestionable que Villar Palasí llegó al ministerio auspiciado por el grupo tecnócrata del Gobierno, en cuyo entorno había realizado buena parte de su carrera política. Sin embargo, no creemos que se le pueda adscribir, en sentido estricto y sin matices, a ningún grupo de los que concurrían en los círculos de poder de los años sesenta. Hombre de gran solvencia intelectual y profesional, católico, humanista y dialogante, mantuvo un alto nivel de independencia ideológica y política a lo largo de su vida pública y particularmente en su gestión al frente del ministerio. Él mismo declaraba en una entrevista realizada por la periodista Maite Ducajú y publicada en el Diario Levante-El Mercantil Valenciano en junio de 2008, lo siguiente: "Yo no era apolítico, pero no tenía un grupo detrás. Ni era del Opus, ni falangista. Era un freelance. Tenía al Consejo de Ministros en contra y si hubiera tardado un año en presentar la propuesta hubiera habido sus más y sus menos».

José Luis Villar Palasí nació en Valencia, en el castizo barrio de Ruzafa, el 30 de octubre de 1922. Colegial del Colegio Mayor San Juan de Ribera de Burjassot, se licenció en Derecho, con premio extraordinario, y en Filosofía y Letras por la Universidad de Valencia en 1945. En 1947 ingresó por oposición, con el número uno de su promoción, en el Cuerpo de Letrados del Consejo de Estado. En 1954 se doctoró Cum Laude y premio extraordinario de doctorado por la Universidad Central de Madrid con su tesis La evolución del justo precio en el derecho administrativo. Vinculado al CSIC, fue miembro del Patronato Marcelino Menéndez Pelayo de dicha institución. Catedrático de derecho administrativo de la Universidad de Madrid desde 1965, de su abundante obra escrita sobre su especialidad académica se ha destacado su solidez, erudición y gran originalidad, «la fusión de perspectivas para el análisis de las instituciones. Villar hace algo que está al alcance de muy pocos, combinar perspectivas. Sus análisis son, al mismo tiempo y sin fisuras, históricos, políticos, económicos, jurídicos, lingüísticos y sociológicos». ${ }^{19}$ Entre 1962 y 1965 fue subsecretario del Ministerio de Comercio, con Alberto Ullastres como ministro. Persona de gran curiosidad intelectual y excelente trato humano, dominaba una decena de idiomas, entre ellos chino y, por supuesto, valenciano. Entre 1965 y 1968 ocupó la Dirección Técnica del

\footnotetext{
19 Alberto Ruiz Ojeda, «José Luis Villar Palasí: in memoriam», Revista de Administración Pública 188
} (2012): 10 . 
Instituto de Estudios Administrativos del Centro de Formación y Perfeccionamiento de Funcionarios de Alcalá de Henares, dimitiendo del cargo para ponerse al frente del Ministerio de Educación y Ciencia.

\section{UN FUERO GENERAL DE EDUCACIÓN}

Villar Palasí se hizo cargo del Ministerio de Educación en abril de 1968, no sin alguna reserva personal por su falta de experiencia profesional en el ámbito no universitario y tras manifestar al jefe del Estado sus reticencias por las actuaciones de la fuerza pública en la Facultad de Derecho de la Universidad Complutense, de la que era decano. El jefe del Estado y el resto del Gobierno esperaban del nuevo ministro, catedrático de universidad, que acometiese de manera urgente y prioritaria la reforma de la universidad y tomase las medidas oportunas para apaciguar las aulas.

Este es el encargo que recibió Villar Palasí y de hecho en su discurso de toma de posesión, el 18 de abril, anunció una reforma de las estructuras universitarias para paliar la agitación estudiantil. En su intervención inicial en el Consejo de Ministros, el 22 de mayo, esbozó las primeras medidas encaminadas a este propósito. ${ }^{20}$ Debemos tener en cuenta que hasta, precisamente, la Ley General de Educación y Financiamiento de la Reforma Educativa de 1970 (LGE), en nuestro país se legislaba por tramos educativos: Primaria, Enseñanza Media, Formación Profesional, Universidad. ${ }^{21}$ No es de extrañar, por tanto, que lo que se esperaba del nuevo ministro era una reforma circunscrita al ámbito universitario. El propio Villar Palasí aludía a este asunto en la introducción del llamado Libro blanco, del que alguna cosa tendremos que decir más adelante:

La reforma educativa que se propugna es tremendamente ambiciosa [...]. Sin duda, el tema de la Universidad y el de las llamadas reivindicaciones estudiantiles de tal nivel es el que acapara la atención general [...]. Me atrevo a decir que, con ello, inconscientemente, se está ocultando la raíz de muchos de los males que «se ven» en la Universidad, pero que se encuentran, en gran medida,

\footnotetext{
20 Manuel Fraga Iribarne, Memoria breve de una vida pública (Barcelona: Planeta, 1980), 222.

${ }^{21}$ Aurelio González Bertolín, «En torno al pacto educativo en España», en eds. Marisa Musaio y Roberto Sanz Ponce Sfide educative e riflessione pedagógica internacionale (Milano: Educatt, 2019 ), 110.
} 
en los anteriores niveles educativos [...]. Debo decir, por último, que yo mismo sufrí inicialmente ese error de perspectiva al acceder al ministerio. ${ }^{22}$

Sin embargo, Villar Palasí ha manifestado en alguna ocasión como a raíz de uno de sus primeros viajes como ministro, realizado por tierras de Galicia, al comprobar el lamentable estado de las escuelas, la escasez de medios y las penosas condiciones en las que ejercía su labor profesional el Magisterio comprendió que lo que la realidad del país reclamaba era una reforma integral que situara el sistema educativo a la altura de los tiempos. Sin duda esta experiencia gallega debió influir poderosamente en el ánimo del ministro, pero es razonable pensar que hubiese otros factores determinantes a la hora de tomar la decisión de emprender una reforma integral del sistema educativo. Es sabido que esta aspiración ya fue declarada en 1955 por el entonces ministro de Educación Nacional, Joaquín Ruiz-Giménez, al presentar ante las Cortes su proyecto de Ley sobre Formación Profesional Industrial:

Nosotros quisiéramos lanzar [...] ese Estatuto de Enseñanzas Técnicas y, tal vez, una Ley o Fuero General de la Educación que, desde la Enseñanza Primaria hasta nuestras universidades, represente la decisión firme de que ya nunca más se produzca la ruptura entre los hombres de España porque hayan tenido ocasión de conocerse desde niños y de hacer frente, ligados en una misma ilusión de juventud, al jubiloso combate de la paz sobre la tierra dura, pero maravillosa de la patria nueva. ${ }^{23}$

Por tanto, no se trataba de una idea novedosa. En el transcurso de los debates de la Comisión de Educación de las Cortes Españolas, a propósito, precisamente, del proyecto de la LGE, el procurador Puig Maestro-Amado ${ }^{24}$ recordó que ya en 1953 se había planteado desde distintos órganos del Movimiento la necesidad de un nuevo ordenamiento integral del sistema educativo: «Venimos desde hace años propugnando una

\footnotetext{
${ }^{22}$ Ministerio de Educación y Ciencia. La educación en España. Bases para una política educativa (Madrid: MEC, 1969), 9-10.

${ }^{23}$ Joaquín Ruiz-Giménez Cortés, «Dos nuevas Leyes de Educación», Revista de Educación 33-34 (1955): 18 .

${ }^{24}$ Ezequiel Puig Maestro-Amado, sevillano de nacimiento, licenciado en Ciencias, falangista de primera hora, fue concejal del Ayuntamiento de Madrid y procurador en Cortes (1961-1977).
} 
Ley de Bases. Yo recuerdo que en el año 1953 se celebró una asamblea general de la Delegación Nacional de Educación del Movimiento que ya lo propugnó». ${ }^{25}$

Sí parece claro que la decisión de Villar Palasí de acometer una reforma integral del sistema educativo fue temprana. Tal y como se ha dicho, "a Villar Palasí hay que reconocerle una capacidad de análisis por encima de la media de los ministros y los hombres del régimen». ${ }^{26}$ Para llevar a cabo su propósito se rodeó de un equipo de técnicos solventes, algunos de ellos bastante alejados del espíritu del Movimiento vigente en el establishment político del momento. Cabe mencionar al subsecretario del Ministerio Alberto Monreal Luque; al secretario general Técnico Ricardo Díez Hochleitner, alto funcionario de la Organización de las Naciones Unidas para la Educación, la Ciencia y la Cultura (UNESCO); José Blat Gimeno, inspector de educación y también funcionario de la UNESCO, que fue incorporado por Villar Palasí al equipo ministerial en calidad de vicesecretario general Técnico; Eugenio López López, falangista, director general de Enseñanza Primaria; y como directora general de Enseñanza Media y Profesional a María Ángeles Galino, vinculada a la Institución Teresiana y catedrática de Historia de la Pedagogía de la Universidad Complutense. Suele atribuirse a Ricardo Díez Hochleitner, que había actuado como experto en reformas educativas al servicio de distintos foros e instituciones internacionales, el haber ejercido, bajo la dirección del ministro, como principal impulsor de la LGE, así como de la coordinación de los trabajos previos recogidos en Libro blanco. ${ }^{27}$

Además del equipo ministerial, en especial José Blat Gimeno, que en razón de su cargo desempeñó un papel destacado en la coordinación de los trabajos, también participaron en la elaboración del Libro blanco,

\footnotetext{
${ }_{25}$ Comisión de Educación y Ciencia de las Cortes Españolas. Boletín Oficial de las Cortes Españolas (Apéndice 19. Extracto Oficial de la sesión celebrada el día 1 de abril de 1970): 16.

26 Miguel Ángel Ruiz Carnicer «De la urbanidad a la educación», en La España de Franco (19391975). Cultura y vida cotidiana, Jordi Gracia García y Miguel Ángel Ruiz Carnicer (Madrid: Síntesis, 2001), 325.

27 Así lo señalaba, veinte años después, el propio Díez Hotchleiner: «En la etapa de diseño de la reforma, la primera tarea directamente relacionada con esta fue la elaboración de un informe general o "Libro Blanco" destinado a su publicación y debate. Tal trabajo fue asumido por mí dentro de la Secretaría General Técnica del Ministerio». Ricardo Díez Hotchleiner, «La reforma educativa de la Ley General de Educación. Datos para una crónica», Revista de Educación n. ext. "La Ley General de Educación veinte años después» (1992): 272.
} 
entre otros, Joaquín Tena Artigas, que asumió la parte estadística; el inspector de educación Adolfo Mállo que junto con los catedráticos de universidad Ricardo Marín y Arturo de la Orden abordaron los aspectos pedagógicos; y José Manuel Paredes Grosso que elaboró la parte relativa a la reforma de la Administración Educativa. ${ }^{28}$ Según testimonio de José Blat Gimeno, "contrariamente a lo que se ha escrito alguna vez no participó ningún extranjero en la elaboración del Libro Blanco». Es cierto que en 1969 se constituyó el denominado Comité de Cooperación Internacional para la reforma de la Educación en España, solicitado por el Gobierno español a la UNESCO, del que formaban parte expertos de primerísimo nivel. ${ }^{29} \mathrm{El}$ Comité se reunió por dos veces en España, marzo en Madrid y noviembre en Toledo, pero como precisa el propio José Blat Gimeno, «cuando se celebró la primera se había publicado el Libro Blanco y cuando se celebró la segunda ya se había elaborado el proyecto de Ley de Educación».30

Lo cierto es que el equipo ministerial, reunido en Buitrago en octubre de 1968, concretó la estrategia para la reforma adoptando unos innovadores métodos de trabajo inéditos hasta entonces en la política educativa española. Como es sabido, el Libro blanco, en sus primeras doscientas páginas -dos terceras partes del documento- realizaba, a partir de un riguroso análisis de los factores sociales, culturales y económicos del momento, un demoledor diagnóstico sobre las insuficiencias, contradicciones y desequilibrios del sistema educativo en España. En el último tercio se proponía, para su posterior debate, un texto con las líneas básicas para la reforma.

\footnotetext{
28 José Blat Gimeno ofrece una más amplia relación de los colaboradores que participaron en la elaboración del Libro blanco. Amparo Blat, «Apuntes sobre la elaboración y aplicación de la reforma educativa de 1968-1970», 291.

${ }^{29}$ El Comité de Cooperación Internacional para la reforma de la educación en España estaba presidido por el doctor Gabriel Betancur, exministro de educación de Colombia y embajador de su país ante la UNESCO, y actuó como relator el Doctor P.H. Coombs, exsubsecretario de Estado para Asuntos Culturales del Departamento de Estado de los Estados Unidos. Formaban parte del comité una docena expertos de distintos países, entre ellos, J. Vaizey de Inglaterra, M. Coulon de Bélgica, H. Becker de Alemania, A. Bienayné de Francia, C. Changas de Brasil, El-Koussy de la República Árabe Unida, R. Kapur de la India, G. Gozzer de Italia, J. Perkins de los Estados Unidos y V. Lipatti, embajador de Rumanía ante la UNESCO. La primera reunión se celebró en Madrid entre los días tres al siete de marzo y contó con la asistencia de Villar Palasí. Comité de Cooperación Internacional para la reforma de la educación en España. Informe final (Madrid: Ministerio de Educación y Ciencia, 1969), 15-16.
}

30 Amparo Blat, «Apuntes sobre la elaboración», 292. 
Otro hombre llamado a desempeñar un papel relevante en la reforma del sistema educativo era el subsecretario del Ministerio, Alberto Monreal Luque, madrileño, nacido en 1928, doctor en Ciencias Económicas y profesor adjunto de la Facultad de Económicas de la Universidad de Madrid. En 1956 accedió por oposición al Cuerpo de Economistas del Estado. Hombre de señalada ideología democratacristiana, en 1961 Laureano López Rodó lo incorporó a la comisaría del Plan de Desarrollo en calidad de jefe adjunto del gabinete de estudios, donde destacó como persona dialogante a la vez que profesional eficaz y competente, hasta que en 1965 el nuevo ministro de Obras Públicas, Federico Silva Muñoz lo nombró secretario general técnico de su Ministerio. López Rodó lamentó perderlo en su equipo: «Si nombras a Monreal me haces un pie agua porque es el jefe de Inversiones Públicas del Plan de Desarrollo», ${ }^{31}$ parece ser que le dijo a Silva Muñoz, a lo que este repuso: «Para eso me lo llevo para ordenar la inversión». Sin embargo, Laureano López Rodó recordaba este episodio de manera no del todo coincidente con su colega de gabinete, «le sugerí a Silva que nombrase secretario general Técnico a Alberto Monreal [...] así lo hizo y siempre me agradeció este valioso fichaje». ${ }^{32}$ Nombrado subsecretario de Educación en el primer equipo de Villar Palasí, fue sustituido en el cargo por el propio Ricardo Díez Hochleitner en octubre de 1969 para hacerse cargo de la cartera de Hacienda.

Parece evidente que la misión de Monreal Luque en equipo de Villar Palasí era idear y diseñar los aspectos fiscales que garantizasen la viabilidad económica de la reforma educativa. En sintonía con las teorías del capital humano, inspiradoras en buena medida de las tendencias internacionales del momento en materia educativa, la prosperidad de las naciones dependía del factor humano, cantidad y calidad de la población, pero singularmente de la formación de esta. La educación empezaba a considerarse una inversión de primer orden. El propio Villar Palasí aludió a ello en su discurso a la Comisión de Educación de las Cortes Españolas, pronunciado con motivo de la iniciación del estudio del proyecto de ley. Invocando el criterio de los economistas más reconocidos del mundo, dijo: «La educación no sólo es la más rentable de las inversiones; es algo más que eso; es la preinversión por excelencia de la

\footnotetext{
31 Silva, Memorias politicas, 104.

32 López Rodó, Memorias, 313.
} 
economía de un país». ${ }^{33}$ En este sentido, cabe señalar que la reforma del sistema educativo llevaba aparejado un incremento sustancial del gasto en educación. Así lo justificaba el ministro: «Todo esto va a costar dinero. No excesivo [...] no nos parece pedir mucho al país que [...] dedique cada año menos de un 15 por 100 del Presupuesto nacional a los gastos corrientes del sector educativo». ${ }^{34}$

Más concretamente, en las disposiciones adicionales segunda y tercera del proyecto de ley aparecían fórmulas de financiación de la reforma que serían suprimidas en el texto definitivo después de su paso por la Comisión de Hacienda de las Cortes Españolas, donde se consideró que no se podía sentar el precedente de que el sistema fiscal se modificase en función de una iniciativa concreta del Estado. Esta postura fue defendida por el procurador Cruz Martínez Esteruelas, cercano al sector azul, que andando el tiempo -no mucho- sería ministro de Educación y Ciencia en el último Gobierno de Franco. Ya lo advertía el propio Villar Palasí, que en su discurso de defensa de la Ley General de Educación (LGE) ante los procuradores no hizo grandes esfuerzos por ocultar su decepción: «¿Es que no sabemos todos, ustedes y yo, qué grupos de presión intentaron negarle a esta ley su sustento vital para el futuro?»,35 aludiendo a los sectores vinculados a la estructura del Movimiento que desactivaron los mecanismos previstos en el proyecto de ley para la financiación de la reforma. Veinte años después de la entrada en vigor de la LGE, Díez Hotchleiner escribiría: «faltó voluntad política para una generosa visión de futuro y consiguiente financiación. Esto contribuyó a que muchas cosas se quedaran en el camino».36

Por lo tanto, el enfrentamiento político entre los hombres del Movimiento y los tecnócratas se sustanció a favor de los primeros en el breve tránsito del proyecto de Ley por las Comisiones de Hacienda y Presupuestos de las Cortes Españolas, al suprimirse los mecanismos previstos para la financiación de la reforma. Según los párrafos del proyecto de ley que se cayeron en el texto aprobado por las Cortes, en primer lugar,

\footnotetext{
${ }_{33}$ Comisión de Educación y Ciencia de las Cortes Españolas. Boletín Oficial de las Cortes Españolas (Apéndice 19. Extracto oficial de la sesión celebrada el día 1 de abril de 1970): 11.

${ }^{34}$ Comisión de Educación y Ciencia. Boletín Oficial de las Cortes Españolas (Apéndice 19): 10.

${ }_{35}$ Pamela O’Malley. La educación en la España de Franco (Madrid: Gens, 2008), 30.

${ }^{36}$ Díez Hotchleitner, «La reforma educativa»: 278.
} 
se restablecía el impuesto especial sobre los beneficios de las sociedades mercantiles, por el que se gravaban con un 10\% los beneficios de las empresas cuando estos excediesen del 6\% de su capital social, considerando que este esfuerzo en la tarea educativa redundaría en el desarrollo económico del país. En segundo lugar, se aumentaba el Impuesto General sobre Tráfico de Empresas en lo que afectaba a depósitos bancarios, entidades de crédito y Cajas de Ahorro. Asimismo, se establecía un recargo sobre las retribuciones de los presidentes y consejeros de las empresas y se elevaban los tipos del impuesto general sobre la renta. Por el contrario, la Comisión de Hacienda y Presupuestos aprobó las enmiendas presentadas por los procuradores Díaz-Llanos ${ }^{37}$ y Martín Sanz ${ }^{38}$, según las cuales se establecía un presupuesto de gastos corrientes, para los diez años siguientes, en pesetas constantes y de carácter meramente indicativo, "cuya insuficiencia sería manifiesta» ${ }^{39}$ para la implantación y desarrollo de la reforma. Tal y como lo sintetizaron, no sin alguna ironía, Díaz Hotchleitner y Tena Artigas a la altura de 1978: «la breve actuación de estas dos últimas (Comisiones de Hacienda y Presupuestos) consistió en la supresión de las medidas de reforma fiscal propuestas por el Gobierno».40

\section{BREVE APUNTE SOBRE LA DIRECCIÓN ESCOLAR EN ESPAÑA HASTA 1970}

Amparo Blat, sobrina de José Blat Gimeno, en un trabajo de reciente publicación, aporta un testimonio de su tío, según el cual este mantuvo una fuerte discusión con Díaz Hotchleitner respecto a la supresión de la

\footnotetext{
${ }^{37}$ Rafael Díaz-Llanos y Lecuona (1911-1993). Natural de Tenerife. Doctor en Derecho y Ciencias Políticas y Económicas, jurista, pintor y poeta. Desempeñó el empleo de teniente auditor durante la Guerra Civil. presidente del Consejo de Colegios de Economistas de España entre 1971 y 1979, fue procurador por designación del jefe del Estado entre 1955-1967, y por elección de los colegios profesionales hasta la disolución de las Cortes franquistas en 1977.

${ }_{38}$ Dionisio Martín Sanz (1909-2002). Vallisoletano y militante de las Juntas de Ofensiva Nacional Sindicalista (JONS), junto a Onésimo Redondo, desde los años treinta. Procurador por el tercio sindical entre 1943 y 1977 era, obviamente, un hombre de Falange. Fue uno de los cincuentaisiete procuradores que en noviembre de 1976 votaron en contra del proyecto de Ley para la Reforma Política.

${ }^{39}$ Antonio Viñao Frago, Escuela para todos. Educación y Modernidad en la España del siglo XX (Madrid: Marcial Pons, 2004), 83.

${ }^{40}$ Ricardo Díez Hotchleiner, Joaquín Tena Artigas y Marcelino García Cuerpo, La reforma educativa y la educación permanente (Paris: UNESCO, 1977): 24.
} 
Inspección de EGB y de Bachillerato y sobre la extinción del Cuerpo de Directores, aspectos ambos contemplados en el proyecto de ley que sería sometido a las Cortes. Según José Blat Gimeno «en lo relativo a la Dirección de Centros Escolares, siempre me ha parecido y así lo aduje, que debe confiarse a quienes poseen una formación especializada en las técnicas propias de la función que han de desempeñar». ${ }^{41}$ Finalmente se aceptó la propuesta del propio José Blat Gimeno de mantener la Inspección de EGB y Bachillerato, pero no así la del Cuerpo de Directores, ya que «el propio Ministro que accedió a lo de la Inspección no consideró pertinente aprobar el mantenimiento de los directores como cuerpo al que se ingresaba por oposición». En las próximas páginas trataremos de aportar algunas posibles claves sobre esta cuestión.

Existe un amplio consenso en situar el origen de la dirección escolar en España, al menos en lo que respecta a la enseñanza primaria, en los albores del siglo XX, cuando comienza a extenderse en nuestro país el modelo de escuelas graduadas. ${ }^{42}$ Con anterioridad, la mayoría de los centros de este nivel educativo eran escuelas unitarias servidas por un solo maestro. ${ }^{43}$ Ya en 1918, mediante Real Orden de 2 de marzo, se estableció el reglamento de escuelas graduadas, que contemplaba la figura de los denominados maestros directores, que compaginaban la actividad docente con las tareas directivas, si bien no se requería una formación específica para el desempeño de este puesto.

La Ley de 17 de julio de 1945, en el período ministerial de Ibáñez Martín, estaba radicalmente influenciada por la doctrina pontificia en materia educativa, así como por los distintos palos ideológicos constitutivos del Nuevo Estado franquista. En el segundo párrafo de su exordio ya proclamaba el legislador que «contra la falsía de los improperios y el acerbo vituperar de los que la ignoran o cínicamente la contradicen, la gloriosa tradición pedagógica hispana representa uno de los caudales más valioso de nuestro haber histórico y una de las más preciadas aportaciones a la

\footnotetext{
${ }^{41}$ Amparo Blat Gimeno, «El Llibre Blanc i la Llei General d'Educació de 1970 segons José Blat Gimeno». Educació i Història: Revista d'Historia de l’Educació 36 (2020): 172.

42 Francisco Javier Murillo Torrecilla y Juan Carlos Gómez Martín, «Pasado, presente y futuro de la Dirección Escolar en España: entre la profesionalización y la democratización». REICE-Revista electrónica Iberoamericana sobre Calidad, Eficacia y Cambio en Educación 4,4e (2006): 85.

${ }_{43}$ En 1935 las escuelas de un solo maestro o maestra constituían el 82\% del total, y a la altura de 1965 dicho porcentaje era todavía del 42\%. Viñao, Escuela para todos, 232.
} 
cultura ecuménica», ${ }^{44}$ para precisar en la página siguiente, «la Ley invoca entre sus principios inspiradores, como el primero y más fundamental, el religioso», y un poco más adelante, «además la Escuela de nuestra Patria ha de ser esencialmente española». En este período, a juicio de Antonio Viñao, ${ }^{45}$ se produjo una devaluación académica, retributiva y social del título de maestro, en comparación con el Plan de Formación del Magisterio de 1931, al no exigirse el grado de bachiller para acceder a los estudios de Magisterio. Por añadidura en 1940 se convocaron unas oposiciones de dudoso nivel académico y profesional -y manifiesto carácter político- para cubrir de manera urgente cuatro mil plazas de maestros fallecidos durante la contienda o separados del servicio a causa de la depuración del Magisterio tras el desenlace de la Guerra Civil.

En lo que atañe a la Dirección escolar, la Ley de 1945 también distinguía entre las escuelas unitarias y las escuelas graduadas, con respecto a las primeras, en su artículo setenta y tres, dispone que «el maestro que la regente tendrá plena responsabilidad de su funcionamiento y gobierno, y su régimen interno reflejará, mediante los oportunos registros, cuadernos y diarios, las normas generales de esta Ley». Y con respecto a las segundas, establece que «en las Escuelas de régimen graduado, el funcionamiento general obedecerá a las normas de unidad y estrecha cooperación que fije su Director», señala entre las competencias de este, la disciplina de conjunto, la ordenación académica, la utilización del material y la coordinación de las instituciones complementarias, si bien matiza que estará obligado a atender las propuestas del resto de maestros que integren el Consejo Escolar del centro. Y por lo que respecta al director de las escuelas privadas se establecen algunos requisitos como estar en posesión de la nacionalidad española, conducta religiosa y moral intachables, e informes político-sociales favorables.

Posteriormente, el Estatuto del Magisterio de 1947 establecía para grupos escolares y escuelas graduadas que «el Director es el responsable jurídico de la Escuela y el superior inmediato de los maestros que están bajo su dirección». ${ }^{46}$ Se accede por oposición restringida (cinco años de

\footnotetext{
${ }^{44}$ Ley de 17 de julio de 1945 sobre Educación Primaria (BOE n. ${ }^{\circ} 199$ de 18 de julio de 1945): 385.

45 Viñao, Escuela para todos, 68.

${ }^{46}$ Decreto de 24 de octubre de 1947 sobre Estatuto del Magisterio (Boletín Oficial del Estado n. ${ }^{\circ} 17$ de 24 de octubre de 1947): 239.
} 
antigüedad o estar en posesión de la Licenciatura en Filosofía y Letras, sección Pedagogía). Para los directores de grupos de menos de seis unidades, los directores serían elegidos cada cinco años -no se precisa en el texto legal por quién, pero se deduce que por el Ministerio- entre los profesores del centro que no tengan nota desfavorable. Con respecto a la oposición restringida, se establece que en cada capital de distrito universitario se constituirán dos tribunales "uno para cada sexo», nombrados por el Ministerio, e integrados por un Consejero Nacional de Educación o por un catedrático de cualquier grado de enseñanza, que actuaría como presidente, un profesor numerario de la Escuela de Magisterio, un inspector de Enseñanza Primaria, un profesor de Religión o sacerdote propuesto por la jerarquía eclesiástica y dos directores de grupo escolar propuestos por el Frente de Juventudes o Sección Femenina.

Suele atribuirse a la LGE la ampliación del período de escolarización obligatoria hasta los catorce años del alumno. Pero esto no es exacto, ya que esta medida se implantó por Ley de 1964,47 con Manuel Lora Tamayo como ministro, así como la posibilidad de incorporarse desde este nivel educativo al tercer año de bachillerato elemental o laboral. Posteriormente, la Ley de Reforma de la Enseñanza Primaria de 1965,48 que según el legislador ampliaba, actualizaba y mejoraba la entonces vigente de 1945, elevaba el nivel académico de los estudios de Magisterio exigiéndose a partir de entonces el grado de bachiller superior para el ingreso en las Escuelas Normales, estableciendo además que la enseñanza de las materias comunes se pudiera impartir conjuntamente a alumnos y alumnas. Dos aspectos que, por otro lado, ya había contemplado Plan de Estudios del Magisterio de 1931.

Quedaban, por tanto, sentadas las bases para la profesionalización de la función directiva escolar, que cristalizaría en la creación y reglamentación del Cuerpo de Directores mediante Decreto de 1967.49 Se constituía como Cuerpo Especial de la Administración Civil del Estado,

\footnotetext{
${ }^{47}$ Ley 27/1964, de 29 de abril, sobre ampliación del período de escolaridad obligatoria hasta los catorce años (Boletín Oficial del Estado n. ${ }^{\circ} 107$ de 4 de mayo de 1964).

${ }^{48}$ Ley 169/1965, de 21 de diciembre, sobre reforma de la Enseñanza Primaria (BOE n. ${ }^{\circ} 306$ de 23 de diciembre de 1965).

49 Decreto 985/1967, de 20 de abril, por el que se aprueba el Reglamento del Cuerpo de Directores Escolares (Boletín Oficial del Estado n. ${ }^{\circ} 117$ de 17 de mayo de 1967): 6578.
} 
al que se encomendaba "como misión profesional y específica» el ejercicio de la función directiva, en sus aspectos docentes, económicos y administrativos de los colegios nacionales, los colegios de prácticas de las Escuelas Normales y las agrupaciones escolares de ocho o más unidades. El director era el representante jurídico del centro y el superior inmediato de los maestros, así como el presidente nato del Consejo Escolar. A juicio de José Luis Bernal, esta disposición, junto a la Orden de 10 de febrero de 1967, por la que se aprueba el reglamento de Centros estales de Enseñanza Primaria, «plantearon un modelo de dirección autoritario y burocrático, en el que el Director ha accedido al cargo mediante una oposición y mantiene su puesto de forma vitalicia». ${ }^{50}$

Al Cuerpo de Directores se accedía mediante oposición libre, a la que podían concurrir maestros nacionales con cinco años de servicios o licenciados en Filosofía y Letras con dos años de experiencia, y la realización de un curso de formación de un año que comprendía, entre otras materias, formación en psicopedagogía y sociología, organización escolar y técnicas y prácticas de dirección. Los directores dependían de la Dirección General de Enseñanza Primaria, siendo la inspección el órgano encargado de su supervisión. Es decir, se reafirmaba una cierta profesionalización de la figura del director, lo que puede ser interpretado como un rasgo de la deriva tecnocrática emprendida en los nuevos tiempos, pero al mismo tiempo, de conformidad con la más castiza tradición española, se le sometía a una total dependencia de la Administración Educativa.

\section{EL CONTRASTE DE PARECERES EN TORNO AL ARTÍCULO SESENTA}

Lo cierto es que el Libro blanco en su párrafo 132 aludía a la escasa tradición de nuestro país para el trabajo en equipo, tanto en los equipos de dirección como en los equipos docentes. Y añadía, «se deja notar en muchos casos la inexistencia de equipos específicamente formados para esta función, muy distinta de la propia del profesorado, ya que requiere

\footnotetext{
50 José Luis Bernal Agudo, «La dirección escolar en la segunda mitad del siglo XX: del autoritarismo a la participación», en eds. Julio Ruiz Berrio, Antonio Bernat Montesinos, María Rosa Domínguez Cabrejas y Víctor Manuel Juan Bordoy La educación en España a examen (Zaragoza: Ministerio de Educación y Cultura e Institución «Fernando el Católico», 1999), vol. 1, 540.
} 
una mentalidad gerencial y un conocimiento de las técnicas de la dirección de empresas educativas». ${ }^{51}$

Sin embargo, el artículo sesenta del proyecto de ley que sería presentado por la ponencia ${ }^{52}$ para su discusión, debate y posterior enmienda en la Comisión de Educación y Ciencias de las Cortes Españolas durante la sesión celebrada el día doce de mayo de 1970, estaba redactado en los siguientes términos: «60.1. Todo centro de educación general básica tendrá un director, nombrado de entre sus profesores, por el Ministerio de Educación y Ciencia. El director estará asistido por el claustro de profesores y por un consejo asesor, en el que estarán representadas las asociaciones de padres de alumnos».53

Y en el punto dos del mencionado artículo se enumeraban las funciones del director, aunque de forma genérica y poco precisa, sin duda a expensas de un posterior desarrollo reglamentario por vía de Decreto: «corresponde al director la orientación y ordenación de las actividades del centro y la coordinación del profesorado».

Es decir, que la redacción del artículo sesenta que presentaba la ponencia suponía, de hecho y en la práctica, la desaparición del Cuerpo de Directores, tal y como argumentó el primer procurador en hacer uso de la palabra, Liaño Flores, ${ }^{54}$ que señaló como la creciente complejidad de los centros docentes requería de una especial preparación para su gobierno, lo que había hecho aconsejable reforzar la figura de la dirección,

\footnotetext{
${ }^{51}$ Ministerio de Educación y Ciencia. La educación en España, 72.

${ }_{52}$ La ponencia que informó del proyecto de LGE para su discusión y enmienda en la Comisión de Educación de las Cortes estaba integrada por Jaime Campmany y Díez de Revenga (abogado y periodista, director de la agencia PYRESA), Manuel García Garrido (rector de la Universidad de Santiago de Compostela), Eugenio López López (director general de Enseñanza Primaria), Adolfo Muñoz Alonso (rector de la Universidad Complutense) y Luis Suárez Fernández (rector de la Universidad de Valladolid).

${ }_{53}$ Comisión de Educación y Ciencia (Boletín Oficial de las Cortes Españolas, Apéndice 19): 6.

54 José Manuel Liaño Flores, nacido en Monforte de Lemos en 1921, abogado, fue procurador en Cortes entre 1967 y 1977 y alcalde de La Coruña entre 1977 y 1979. Formó parte del autodenominado Grupo Parlamentario Independiente constituido por una serie de procuradores de distintas procedencias ideológicas en el seno del régimen, que a partir de la primavera de 1975 se caracterizaron por su posicionamiento reformista y consiguieron una cierta dinamización de la vida política del momento a través de sus iniciativas parlamentarias. Su actuación fue particularmente activa durante el debate de la ley para Reforma Política. Miguel Ángel Giménez Martín «Los reformistas del franquismo en las Cortes: el Grupo Parlamentario Independiente» Revista de Estudios políticos 179 (2017): 199-230.
} 
mediante su constitución como Cuerpo Especial de la Administración del Estado. Añadió que el acceso por oposición permitía seleccionar a los mejores y que el curso posterior, previsto en el proceso selectivo, completaba la adecuada formación de los candidatos en técnicas y prácticas directivas. A su juicio el director escolar no podía ser un profesor en ejercicio, sino un profesional plenamente dedicado a las tareas directivas, que concretó en los siguientes aspectos: dirección, control, evaluación del centro, proyección social, promoción de asociaciones, contactos diarios con las familias, orientación profesional, «moderador y orientador del medio ambiente, responsable directo y permanente de los intereses estatales, tanto en el orden pedagógico como en el material».55 Por último, manifestó sus reservas sobre el sistema de elección propuesto por la ponencia, la libre designación por parte del ministerio, ya que dejaba sujeto a una discrecionalidad política que calificó de "peligrosa», lo que debía ser un puesto directivo de carácter técnico y profesional.

Como hemos dicho con anterioridad, el Libro blanco en sus dos terceras partes, página 15 a 199, realizaba un certero diagnóstico de las deficiencias, contradicciones y aun perversidades del sistema educativo a la sazón vigente, y en la segunda parte, página 201 a 244, se ofrecían algunas propuestas para su discusión y debate, que a la postre acabarían constituyendo el andamiaje básico de la LGE. A juicio de Puelles Benítez «la Ley General de Educación no es más que el Libro Blanco articulado». ${ }^{66}$ Y así lo venía a justificar el propio Villar Palasí en el prólogo de la obra, en el que aludía a «una desproporción entre el número de páginas de la primera parte -de naturaleza fundamentalmente crítica- y el de la segunda, en el que se señalan las soluciones ofrecidas». ${ }^{57}$

Por tanto, tenemos que considerar una rara excepción en el proceso de elaboración de la LGE la contradicción entre lo dicho en el párrafo 132 del Libro blanco, la falta de formación y técnicas de trabajo en equipo para la función directiva, y la redacción del artículo sesenta que suprimía el Cuerpo de Directores y, por consiguiente, la formación específica vinculada al proceso selectivo. Es decir, que el artículo sesenta del

\footnotetext{
55 Comisión de Educación y Ciencia (Boletín Oficial de las Cortes Españolas Apéndice 43): 7.

56 Puelles, «Tecnocracia y política en la reforma educativa de 1970»: 23.

${ }^{57}$ Ministerio de Educación y Ciencia. La educación en España, 8.
} 
proyecto de ley se distanciaba diametralmente del análisis realizado en el Libro blanco en lo tocante a la dirección escolar. No parece lógico, además, que una reforma educativa de inequívoco aroma tecnocrático renunciase, apenas tres años después de su reglamentación, a un Cuerpo de Directores definido por la selección, la profesionalización y la especialización de sus miembros en el desempeño de sus funciones.

¿A qué pudo deberse este cambio? Se ha dicho, y compartimos esa idea, que un cuerpo directivo profesional y permanente sería un elemento menos manejable por la Administración educativa que un director temporal, nombrado y cesado por ella. ${ }^{58}$ A juicio de Antonio Viñao, la supresión del cuerpo de directores fue una de las cuestiones más controvertidas de la LGE, de la que «todavía está por analizar los grupos implicados y las estrategias e interesas en juego». ${ }^{59} \mathrm{Al}$ margen de las tensiones políticas en el seno del propio ministerio, nuestra hipótesis es que la decisión de suprimir el Cuerpo de Directores no fue ajena a las reuniones de expertos internacionales, celebradas en Madrid y Toledo los meses de marzo y noviembre de 1969, en las que se recomendaba actualización, innovación y movilidad en el ejercicio de ciertas responsabilidades profesionales. Según el testimonio de José Blat Gimeno, que hemos mencionado con anterioridad, cuando se celebró la primera reunión ya se había publicado el Libro blanco, efectivamente, pero no se había elaborado el proyecto de ley.

En el Informe final del Comité de Cooperación Internacional para la reforma de la Educación en España, a cuya primera reunión asistieron Villar Palasí y Díez Hochleitner, en lo referido a la actualización de los profesionales, se concluía que a fin de proteger la seguridad y el bienestar públicos debían adoptarse ciertas medidas que asegurasen una permanente actualización de los mismos, singularmente a los que desempeñaban responsabilidades «en sectores críticos para la sociedad -tales como la medicina y la educación», favoreciendo que se incorporasen nuevas ideas y métodos y propiciando así un cambio constante. Y añadía que la licencia de ejercicio profesional debiera tener una duración

\footnotetext{
58 Antonio Viñao Frago, «La Educación General Básica. Entre la realidad y el mito», Revista de Educación n. ${ }^{\circ}$ ext. «La Ley General de Educación veinte años después» (1992): 59.

59 Antonio Viñao Frago, «La dirección escolar: un análisis genealógico y cultural», Educação, XXVII, 2 (53) (2004): 388.
} 
limitada y «expirar automáticamente como los pasaportes [...] esta es ya una práctica generalmente aceptada en algunos sectores, por ejemplo, con respecto a los pilotos de líneas de aeronaves». ${ }^{60}$

Mientras que el debate del proyecto de ley en la Comisión de Hacienda de las Cortes, a resultas del cual se suprimieron los mecanismos previstos para el financiamiento de la reforma, se sustanció en un solo día, dos de julio, los debates de la Comisión de Educación y Ciencia, que se iniciaron el uno de abril, se dilataron a lo largo de tres meses, en un ambiente que ha sido calificado de «anodino» ${ }^{61} \mathrm{y}$ "de gran mediocridad».62 Y, efectivamente, una vez revisado el Diario de Sesiones de la Comisión de Educación y Ciencia, no hemos identificado ninguna escaramuza dialéctica digna de mención entre tecnócratas y azules. Fue precisamente el artículo sesenta el que concitó un mayor número de enmiendas, 76, de las cuales 53 se manifestaron abiertamente en contra de la redacción propuesta por la ponencia.

Las intervenciones de los procuradores que defendieron sus enmiendas seguían la estela de lo argumentado por Liaño Flores en la primera intervención de la sesión. Defensa de la pervivencia del Cuerpo de Directores por considerar que se trataba de una función de carácter predominante técnico y gerencial, y que por consiguiente requería de un adecuado proceso de selección y formación. Se insistía en que el acceso mediante oposición era el único procedimiento que garantizaba la necesaria profesionalidad e independencia para ejercer el cargo de director. La procurador -como se decía entonces- Véglison Jornet ${ }^{63}$ afirmó que era absolutamente necesario mantener el cuerpo de directores porque de lo contario cada vez que cambiase un director general, serían relevados de su cargo muchos directores, y se formuló la siguiente pregunta retórica «¿Cómo va a estar dotado de autoridad un director al que no ampara más circunstancia que haber sido elegido por sus compañeros o designado a dedo?». Los procuradores que le siguieron en el uso de la

\footnotetext{
${ }^{60}$ Comité de Cooperación, Informe final, 8.

61 Viñao, Escuela para todos, 82.

62 Puelles, Educación e ideología en la España contemporánea, 350.

63 Josefina Véglison Jornet (1915-1992), natural de San Sebastián, era enfermera y secretaria de la Sección Femenina en Madrid entre 1936-1939. Fue procuradora en Cortes por el tercio familiar entre 1967 y 1971.
} 
palabra abundaron en la "peligrosa discrecionalidad» que suponía el nombramiento del director por el Ministerio. Varias intervenciones hicieron hincapié en que el director requiere una formación especializada y, por lo tanto, no podía ser considerado como un igual a los profesores sometidos a su autoridad. El procurador Merino García ${ }^{64}$ afirmó que toda función directiva lleva consigo la necesidad de un dirigente, además «se puede ser un director magnífico y un profesor mediano y viceversa». ${ }^{65} \mathrm{Y}$ este fue el tenor de la práctica totalidad de las enmiendas presentadas: rechazar el texto propuesto por la ponencia y mantener el cuerpo de directores.

Hubo que esperar hasta la enmienda número 52, defendida por Mayor Zaragoza, ${ }^{66}$ para escuchar algunos argumentos que diesen cobertura al texto presentado por la ponencia. Este procurador afirmó que un maestro que dejase de ejercer la docencia no podría considerarse un auténtico maestro, por tanto, la función directiva debía ser regulada de forma que fuese inseparable del ejercicio efectivo del magisterio. Se preguntó cómo iba a poder orientar la docencia, los métodos de enseñanza y los sistemas de evaluación, un profesor que se vaya alejando progresivamente de la realidad docente del día a día, «el director escolar que haya demostrado su calidad y capacidad, que continúe, pero sin bula de permanencia ni dirección vitalicia».67 Así pues, en una intervención en cierto modo premonitoria de lo que serían sus responsabilidades como secretario general de la UNESCO en el último cuarto del siglo veinte, el procurador Mayor Zaragoza coincidió con el Informe final del Comité de Cooperación Internacional para la reforma de la Educación en España, solicitado por el Gobierno español a la UNESCO el año anterior, en lo referido a la conveniencia de propiciar la actualización y movilidad en el desempeño de sus funciones de los profesionales de la educación.

\footnotetext{
${ }^{64}$ Rafael Merino García nació en Málaga, en 1935, en el seno de una familia de trabajadores. Estudió Derecho con una beca sindical e hizo su carrera política en el entorno del sindicalismo vertical. Fue uno de los fundadores del Grupo Parlamentario Independiente, que promovió diversas iniciativas reformistas en las postrimerías del franquismo.

${ }_{65}$ Comisión de Educación y Ciencia (Boletín Oficial de las Cortes Españolas. Apéndice 42): 27.

${ }^{66}$ Federico Mayor Zaragoza (Barcelona, 1934). Es doctor en Farmacia por la Universidad Complutense y catedrático de esta misma especialidad en la Universidad de Granada. Vicepresidente del CSIC en 1971, fue ministro de Educación y Ciencia (1981-1982). En 1987 la 24ª Conferencia General de la UNESCO lo eligió director general, cargo que desempeñaría hasta 1999.

${ }^{67}$ Comisión de Educación y Ciencia (Boletín Oficial de las Cortes Españolas. Apéndice 42): 38.
} 
A partir de ahí, García Garrido, miembro de la ponencia, justificó la redacción propuesta en base a la movilidad, ya que una sociedad moderna, dijo, exige un estímulo de los mejores frente a estos cuerpos o castas. Aludió también a la necesaria renovación generacional, «es preferible que estos cargos, después de unos años de ejercicio, sean desempeñados por personas de las generaciones nuevas, con nuevos estímulos, con nuevo entusiasmo y con nuevo afán de superación».68 Finalmente, otro miembro de la ponencia, el procurador Campmany Díez de Revenga, propuso una nueva redacción para el artículo:

60.1. Todo centro de educación general básica tendrá un director asistido por el claustro de profesores y por un consejo asesor, en el que estarán representados los padres de los alumnos. El director será nombrado, entre los profesores titulares del centro, por el Ministerio de Educación y Ciencia, de acuerdo con las normas reglamentarias y oídos el claustro y el consejo asesor. ${ }^{69}$

El nuevo texto modificaba en poco el que inicialmente se había sometido a discusión en la Comisión de Educación y Ciencia de las Cortes, al menos aparentemente, ya que el «de acuerdo con las normas reglamentarias» invitaba a un amplio desarrollo reglamentario del artículo. En cualquier caso, el artículo 60, conforme a la redacción finalmente propuesta por la ponencia fue aprobado, con doce votos en contra, cuando «eran las nueve y cincuenta minutos de la noche». En la sesión del día siguiente, 13 de mayo, se aprobó sin mayores objeciones el punto dos del artículo 60 en los términos propuesto por la ponencia «corresponde al director la orientación y ordenación de las actividades del centro y la coordinación del profesorado». A continuación, el procurador Martínez Estenaga ${ }^{70}$ tomó la palabra para hacer un análisis del artículo aprobado en términos poco habituales en el lenguaje parlamentario del momento: nos hemos «cepillado al cuerpo de directores escolares en esta enmienda». ${ }^{71}$

\footnotetext{
${ }^{68}$ Comisión de Educación y Ciencia (Boletín Oficial de las Cortes Españolas. Apéndice 42): 41.

${ }^{69}$ Comisión de Educación y Ciencia (Boletín Oficial de las Cortes Españolas. Apéndice 42): 53.

${ }^{70}$ Dirigente del Sindicato de Trabajadores y Técnicos de la Construcción, dependiente de la estructura del Movimiento, se situó en posiciones reformistas en los primeros tiempos del postfranquismo.

${ }^{71}$ Comisión de Educación y Ciencia (Boletín Oficial de las Cortes Españolas. Apéndice 43): 6.
} 


\section{A MODO DE EPÍLOGO}

José Luís Villar Palasí acometió una reforma integral del sistema educativo rodeándose de un equipo de técnicos competentes y adoptó unos métodos de trabajo inusitados hasta entonces en la política española. La LGE de 1970 estableció la enseñanza general, básica, única y obligatoria, igual para todos, desde los seis a los trece años, ambos incluidos. Un bachillerato postobligatorio, de tres años de duración, de carácter unificado y polivalente. Modernizó los métodos pedagógicos prescribiendo innovaciones como el trabajo en equipo, la atención individualizada, los métodos activos, el fomento de la iniciativa creadora o la evaluación continua. Diseñó un nuevo sistema educativo interrelacionado -con alguna reserva- entre sus ciclos, niveles y grados, como es propio de los sistemas educativos democráticos. Asimismo, afirmó las competencias del Estado en materia educativa y trató de propiciar una mayor participación de los padres de los alumnos en los centros docentes. Con respecto a la formación del profesorado convirtió a los maestros en diplomados universitarios y promovió una reforma de la formación inicial y continua del profesorado de enseñanza media. Se instituyó el Certificado de Aptitud Pedagógica (CAP) para mejorar la competencia didáctica y pedagógica del profesorado de este nivel educativo y se crearon los Institutos de Ciencias de la Educación (ICEs), dependientes de las universidades, con el fin de fomentar la investigación educativa y la formación permanente del profesorado. Fue mérito de Villar Palasí y su equipo saber comprender, todavía en los últimos años del franquismo, que el anticuado sistema educativo español ya no respondía mínimamente a las necesidades de la sociedad española de los años del desarrollismo.

La reforma impulsada por Villar Palasí seguía la estela de las reformas educativas emprendidas por los países avanzados a partir del final de la Segunda Guerra Mundial. Inspiradas en las teorías del capital humano, partían de la consideración de la educación como un factor clave para el desarrollo económico y la cualificación profesional. La LGE de 1970, con sus luces, sombras e incumplimientos sobre lo inicialmente previsto, dotó al país de un sistema educativo perfectamente homologable al del resto de países desarrollados, aunque es cierto que con veinte años de retraso. También cabe recordar que no pocos de los aspectos fallidos de la reforma se debieron, tal y como hemos analizado en el presente trabajo, a la desactivación de los mecanismos previstos para su financiación por parte de los sectores políticos contrarios a la misma. Por otro lado, la implantación y 
desarrollo normativo de la LGE se llevó a cabo durante los últimos gobiernos del tardofranquismo que, al margen de otras consideraciones de orden político e ideológico, carecían del nervio reformista de Villar Palasí y su equipo ministerial.

Por último, con respecto a la supresión del Cuerpo de Directores, propiciada por el texto definitivo de la LGE, hemos tratado de demostrar cómo, a pesar de que desde un supuesto estrictamente tecnocrático, no solo el mantenimiento, sino la potenciación de un cuerpo directivo profesional parecía la opción más ortodoxa y consecuente con el espíritu y los objetivos de la reforma, pudo tener un papel relevante el Informe final del Comité de Cooperación Internacional para la reforma de la Educación en España, solicitado por el Gobierno español a la UNESCO, que abogaba por la adopción de medidas que asegurasen la movilidad, la renovación y la formación permanente de los profesionales que desempeñasen puestos de singular valor estratégico en el sistema educativo.

\section{Nota sobre los autores}

Aurelio González Bertolín es doctor en Ciencias de la Educación por la Universidad de Valencia. Profesor de Teoría e Historia de la Educación en la Universidad Católica de Valencia. Vicepresidente primero del Colegio Oficial de Pedagogos y Psicopedagogos de la Comunitat Valenciana. Editor de Crónica. Revista Científico Profesional de la Pedagogía y Psicopedagogía. Vocal de la Junta Directiva de la Sociedad Española de Pedagogía (SEP). Líneas de investigación: formación del profesorado e historia y política educativas.

Roberto Sanz Ponce es doctor en Ciencias de la Educación por la Universidad de Valencia. Profesor de Teoría e Historia de la Educación en la Universidad Católica de Valencia. Secretario del Instituto Universitario de Teoría de la Educación. Director de la revista Edetania. Estudios y Propuestas Socioeducativas. Vocal de la Junta de Gobierno del Colegio Oficial de Pedagogos y Psicopedagogos de la Comunitat Valenciana. Evaluador de diferentes revistas, tanto nacionales como internacionales, en el ámbito de la educación. Líneas de investigación: formación del profesorado y competencias docentes. 


\section{REFERENCIAS}

Bernal Agudo, José Luis. «La dirección escolar en la segunda mitad del siglo XX: del autoritarismo a la participación», en La educación en España a examen vol. 1, editado por Julio Ruiz Berrio, Antonio Bernat Montesinos, María Rosa Domínguez Cabrejas y Víctor Manuel Juan Bordoy (537-415). Zaragoza: Ministerio de Educación y Cultura e Institución «Fernando el Católico», 1999.

Blat Gimeno, Amparo. «El Llibre Blanc i la Llei General d'Educació de 1970 segons José Blat Gimeno». Educació i Història: Revista d'Historia de l'Educació, 36 (2020): 161-175.

Blat Gimeno, José. «Apuntes sobre la elaboración y aplicación de la reforma educativa de 1968-1970». Revista de Educación n. ${ }^{\circ}$ ext. "La Ley General de Educación veinte años después» (1992): 289-296.

Calvo Serer, Rafael. España sin problema. Madrid: Rialp, 1957.

Comité de Cooperación Internacional para la reforma de la Educación en España, Informe final. Madrid: Ministerio de Educación y Ciencia, 1969.

Díaz García, Elías. Pensamiento español en la era de Franco (1939-1975). Madrid: Tecnos, 1983.

Díez Hochleitner, Ricardo. «La reforma educativa de la Ley General de Educación de 1970. Datos para una crónica». Revista de Educación n. ${ }^{\circ}$ ext. «La Ley General de Educación veinte años después» (1992): 261-278.

Díez Hotchleiner, Ricardo, Joaquín Tena Artigas y Marcelino García Cuerpo. La reforma educativa y la educación permanente. París: UNESCO, 1977.

Doval Huecas, Gregorio. Los últimos años del franquismo (1969-1970). Madrid: Síntesis, 2007.

Fontán Pérez, Antonio. Los católicos en la Universidad Española actual. Madrid: Rialp, 1961.

Fraga Iribarne, Manuel. Memoria breve de una vida pública. Barcelona: Planeta, 1980.

Franco Salgado-Araujo, Francisco. Mis conversaciones privadas con Franco. Barcelona: Planeta, 1976.

Giménez Martín, Miguel Ángel. «Los reformistas del franquismo en las Cortes: el Grupo Parlamentario Independiente». Revista de Estudios Políticos 179 (2017): 199-230.

González Bertolín, Aurelio. «En torno al pacto educativo en España». En Sfide educative e riflessione pedagógica internacionale, editado por Marisa Musaio y Roberto Sanz Ponce., 107-118. Milano: Educatt, 2019.

González Bertolín, Aurelio y Roberto Sanz Ponce. «"Excluyentes” y "comprensivos”. Joaquín Ruiz-Giménez y los orígenes de la extensión de la Enseñanza Media en España». Educació i Història 32 (2018): 89-113. 
González Cuevas, Pedro Carlos. «La derecha tecnocrática». Historia y Política: Ideas, Procesos y Movimientos Sociales 18 (2007): 23-48.

Laín Entralgo, Pedro. España como problema. Madrid: Escelicer, 1949.

López Rodó, Laureano. Memorias. Barcelona: Plaza y Janés, 1990.

Lora Tamayo, Manuel. Lo que yo he conocido. Recuerdos de un viejo catedrático que fue ministro. Cádiz: Ingrasa, 1993.

Miguel Rodríguez, Amando de. Sociología del franquismo. Análisis ideológico de los Ministros del Régimen. Barcelona: Euros, 1975.

Ministerio de Educación y Ciencia, La educación en España. Bases para una reforma educativa. Madrid: MEC, 1969.

Murillo Torrecilla, Francisco Javier y Juan Carlos Gómez Martín. «Pasado, presente y futuro de la Dirección Escolar en España: entre la profesionalización y la democratización». REICE-Revista Electrónica Iberoamericana sobre Calidad, Eficacia y Cambio en Educación 4, 4e (2006): 61-99.

O’Malley, Pamela. La educación en la España de Franco. Madrid: Gens, 2008.

Palacios Tapias, Jesús. Las cartas de Franco. Madrid: La Esfera de los Libros, 2005.

Pérez-Embid Tello, Florentino. "Ante la nueva actualidad del "Problema de España”». Arbor 45-46 (1949): 149-160.

Puelles Benítez, Manuel de. «Tecnocracia y política en la reforma educativa de 1970». Revista de Educación n. ${ }^{\circ}$ ext. "La Ley General de Educación veinte años después» (1992): 13-29.

Puelles Benítez, Manuel de, Educación e ideología en la España contemporánea. Madrid: Tecnos, 1999.

Ruiz Carnicer, Miguel Ángel. «De la urbanidad a la educación». En Jordi Gracia García y Miguel Ángel Ruiz Carnicer, La España de Franco (1939-1975). Cultura y vida cotidiana (319-338). Madrid: Síntesis, 2001.

Ruiz-Giménez Cortés, Joaquín. «Dos nuevas Leyes de Educación». Revista de Educación 33-34 (1955): 1-19.

Ruiz Ojeda, Alberto. «José Luis Villar Palasí: in memoriam». Revista de Administración Pública 188 (2012): 9-13.

Silva Muñoz, Federico. Memorias políticas. Barcelona: Planeta, 1993.

Tusell Gómez, Javier. Historia de España en el siglo XX. III La Dictadura de Franco. Madrid: Taurus, 2000.

Viñao Frago, Antonio. «La Educación General Básica. Entre la realidad y el mito» Revista de Educación n. ${ }^{\circ}$ ext. "La Ley General de Educación veinte años después» (1992): 47-71.

Viñao Frago, Antonio. Escuela para todos. Educación y modernidad en la España del siglo XX. Madrid: Marcial Pons, 2004.

Viñao Frago, Antonio. «La dirección escolar: un análisis genealógico y cultural» Educaçäo, XXVII, 2 (53) (2004): 367-415. 